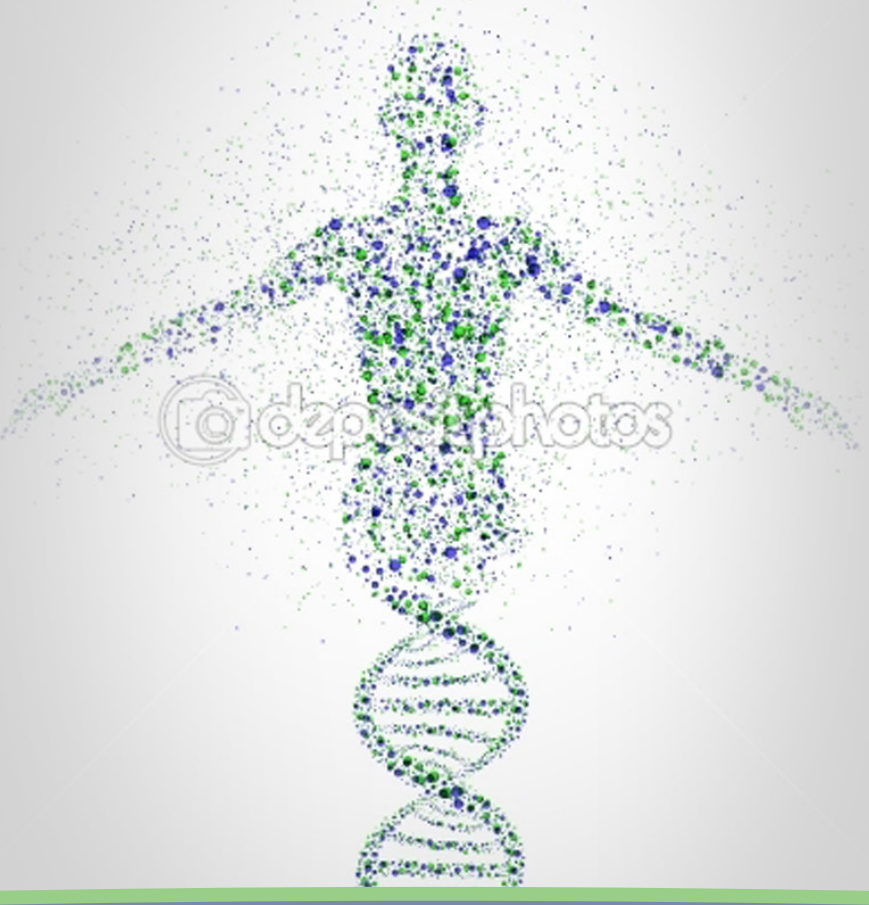

EIDOS, 5

Marzo • Agosto 2012, 47-52

ISSN:1390-499X

elSSN:1390-5007

\title{
CIENCIA E INVESTIGACIÓN ENCARNADA
}

E. Trigo ${ }^{1}$, Universidad Tecnológica Equinoccial

Recepción/Received: 2011-11-28

Aceptación/Accepted: 2012-04-25

Publicado/Published: 2012-08-20

Resumen - A partir de un análisis de lo que significa "conocer" en el mundo complejo y crítico de hoy en día, el artículo aborda y desarrolla una propuesta sobre ciencia e investigación encarnada a la luz de la corporeidad y motricidad humana (CMH), fundamentada en autores de diversas ámbitos y de la experiencia investigativa de la autora.

Palabras clave - ciencia-conocimiento encarnado, investigación encarnada, corporeidad, motricidad humana.

Abstract - From an analysis of what it means to "know" in the critical and complex world of today, the article discusses and develops a science and research embodied in the light of corporeality and human movement, based on various authors areas and research experience of the author.

Keywords - embodied knowledge science, research embodied, corporeal, human movement.

'Eugenia Trigo Aza, etrigo@ute.edu.ec, Docente de Posgrados, Universidad Tecnológica Equinoccial 
Con Ciencia-conocimiento

encarnado

Crisis!!! Crisis financiera, crisis económica, crisis ecológica, crisis de valores, crisis del conocimiento, ¿no será una crisis civilizatoria?, ¿no será la oportunidad, que la vida, nos da a los humanos, para buscar otras vías de ser y estar en el mundo? Mas ¿tenemos la capacidad de darnos cuenta, percibir, tomar consciencia, afrontar los miedos y atrevernos a inventar otros mundos? ¿Estamos dispuestos a enfrentar el problema como humanos, como gobiernos, como naciones, como pueblo-humano? Si los problemas son otros, ¿no serán también otros los caminos a emprender y las preguntas a cuestionar? ¿Hemos llegado hasta el siglo XXI para abandonarnos a la desesperanza y al desasosiego?, ¿será que "don dinero" no nos dejará pensar, imaginar, soñar, proponer y organizar un mundo distinto para la diferencia y la inclusión?, ¿será que todavía no hemos construido conocimiento suficiente para abordar las cuestiones fundamentales que en estos momentos nos asolan?

¿Para qué tantos años de escolaridad, tantas universidades, tanta inversión en educación, investigación, tecnología y desarrollo si no somos capaces de afrontar y enfrentar esta crisis?, ¿nos queda algo por hacer a los investigadores?, ¿en dónde estamos atrapados para sentir que nos faltan las ideas?

Con el ánimo de contribuir, desde nuestra ubicación terrícola, a la construcción de conocimiento pertinente y contextual, es que nos desafiamos a continuar hablando-escribiendo de investigación. Porque ha sido y es la investigación uno de mis placeres y razones de mi existencia. Mas cuando hablo de investigación, lo hago desde mi vivencia corpórea² ${ }^{2}$ desde lo aprendido encarnadamente, desde lo aplicado en el día a día, en las aulas, los proyectos, la calle, la casa, los viajes y publicado en diversos años y contextos (Aristizábal \& Trigo, 2009).

El Diccionario de la Real Academia Española (DRAE) nos dice que Investigación es: "Indagación, exploración, pesquisa, busca, averiguación, sondeo, escudriñamiento; e Investigar: poner en claro, seguir la pista, sacar en limpio, dar un toque, inquirir, indagar, averiguar".

Podemos destacar que, por un lado, investigación nos habla de indagación y exploración, es decir de una

2 Corpóreo/a: adjetivo calificativo de "corporeidad": nuestro ser en el mundo. (Trigo y otros, 1999). actitud de búsqueda y descubrimiento; y por otro, investigar hace énfasis en seguir la pista e inquirir; esto es, es un acto de preguntar y avanzar en un camino que se construye a sí mismo. Pero esta búsqueda va más allá de la simple pesquisa por descubrir la realidad que nos rodea y conforma, está encaminada a ser la base que permite al ser humano, ante todo, comprenderse a sí mismo, que le permite vislumbrar y seguir su propia trayectoria como humano, pero reconociendo que su búsqueda no es solitaria, que la hace en íntima relación consigo mismo, con sus congéneres y con la naturaleza que lo rodea. En palabras de la Motricidad ${ }^{3}$, el ser humano se hace humano en su interacción con el yo-otro-cosmos. Desde esta perspectiva, ¿qué podemos aprender de la intención humana de conocer? ¿Para qué debe servir la investigación? Desde mi mirada, la investigación debe servir para contribuir a construir un mundo más amable, respetuoso los unos con los otros, lleno de sueños cercanos a las realidades que contribuya a vivir en armonía.

Desde la Motricidad Humana se considera que la investigación debe ser un proceso de enamoramiento entre la búsqueda constante por lo que somos y aquella producción de conocimiento que hace ciencia-conocimiento encarnado o logos encarnado. Entendemos el conocimiento desde la perspectiva de Morin (1994) como "actividad por la cual, el ser humano toma consciencia de los datos de la experiencia y procura comprenderlos o explicarlos. El acto de conocer es al mismo tiempo, biológico, cerebral, espiritual, lógico, lingüístico, cultural, social, histórico; no puede disociarse de la vida humana y de las relaciones sociales".

Nos ubicamos, desde hace décadas, como investigadores en una ciencia/conocimiento ético-político (la motricidad humana) que supere (no que desconozca) todos los "ismos" y fragmentaciones de la tradicional cultura egocéntrica de la Europa en que nos hemos formado. Vivir en Latinoamérica, no puede ser un acaso y un solapamiento, debe ser una oportunidad para auto-reconocer lo propio y ajeno. Es desde esta interculturalidad que estamos colaborando con el mundo académico-político en la construcción de conocimiento pertinente para este momento histórico ${ }^{4}$.

Las ciencias cognitivas, las neurociencias, la fenomenología y neurofenomenología, los avances de la física

\footnotetext{
${ }^{3}$ Motricidad (humana). El ser humano en su complejidad que se moviliza (siente, piensa, hace, sueña, se comunica) desde el aquí y el ahora a la trascendencia y de ésta al aquí y al ahora, en la relación yo-otro-cosmos. Movimiento intencional hacia la trascendencia. Praxis creadora. Energía que me impulsa a vivir (Sérgio y otros, ).
} 
(de la física newtoniana a la física cuántica) y la matemática (de la geometría euclidiana a la fractal y la cuarta dimensión), las teorías de sistemas y la complejidad, los diálogos entablados entre los místicos-orientales-budistas y los científicos-occidentales, no pueden ser sólo aportes teóricos para regocijo de los intelectuales y científicos. Son verdaderas rupturas paradigmáticas, ontológicas, epistémicas y metodológicas que nos colocan en "crisis" respecto a la propia cosmovisión y construcción del conocimiento. Ya no podemos negar la evidencia, sólo nos queda tratar de comprender y aplicar a la Vida -nuestra vida-, estas "nuevas" contribuciones del saber humano.

Hay un mensaje que todo el mundo debiera comprender hoy por hoy, que esa historia del antagonismo o de la dualidad mente-cuerpo se acabó. Que eso es puramente un reflejo adquirido, que desde el punto de vista científico, filosófico y culturalmente -dicho así en grande-, no hay manera ni ninguna razón para confundir...Decir que hay una especie de contradicción o de separación entre la mente y el cuerpo tendría que ser lo mismo que pensar que hay una contradicción entre el movimiento del caballo y sus patas (Varela 2000b).

¿Qué significa "conocer" hoy en día? Un trabajo exhaustivo al respecto, basado en investigadores de la más alta talla nos lo presenta Sergio Toro en una de sus últimas publicaciones (2010).. Conceptos como mente encarnada, logos encarnado, enacción, corporeidad, motricidad, creatividad son los que están en el soporte de la ciencia/conocimiento encarnado.

El primer desafío a enfrentar, como seres humanos creadores de historia, es la ampliación de la capacidad de pensar que conlleva la dimensión somática. Esto nos ofrece "un nuevo acceso a la relación corporal con el mundo a través de los sentidos, más allá de la función de la consciencia y del lenguaje" (Conill, citado por Zemelman, 2005, pág...).

¡Qué difícil nos lo ha puesto la historia! Primero nos "convencen" que la res extensa es independiente de la res cogitans, que la ciencia no es arte, que el arte no es filosofía, que el investigador (sujeto) debe abstraerse de

${ }^{4}$ Vivimos un momento histórico caracterizado por un desarrollo capitalista carente de todo equilibrio... el afán de lucro y lo que acompaña a éste; la voracidad e irracionalidad en el uso de los recursos, pero sin contrapeso... recuperar la idea de que más importante que el conocimiento es asumir una postura de consciencia que convierta la duda, el límite o el bloqueo en nuevas posibilidades... Como nunca, no podemos hoy aceptar quedarnos dentro de las certezas protegidas por los límites de lo establecido, sino más bien embestirlos desde la búsqueda de utopías que respalden una más plena realización del hombre y fortalezcan su consciencia protagónica (Zemelman 2005: 22). la cosa a ser investigada (objeto) para que su investigación sea validada y fiable por la comunidad científica. Y ahora, después de haber aprendido muy bien la tarea, nos cambian las preguntas, modifican el contexto, nos mudan las teorías interpretativas de la realidad. ¿Cómo re-acomodarnos?, ¿cómo ser capaces de continuar la creación humana?, ¿quién se atreve a dar el primer paso en los lugares habituales de vida personal-profesionalacadémica? Pero, si nos llamamos investigadores, o intelectuales, o científicos, o simplemente seres humanos, no nos queda más que cumplir con nuestra responsabilidad histórica: jser creadores de realidades, ser utópicos y acrónicos!

Conocemos-vivimos a través de los sentidos (sujetomedio), comprendemos desde y con nuestra corporeidad (nuestro complejo ser-en-el-mundo), interpretamos en nuestra motricidad (corporeidad en-acción hacia la trascendencia), proyectamos con la creatividad (lo que está más allá de lo visible). La razón ya no es opuesta a la no-razón (Botero Uribe, 2000, pág...) sino que es una forma integrada de pensar, es un pensar epistémico y no un pensar teórico. ¿Seremos capaces, los seres humanos de este siglo, de comprender en la piel y no solamente con la razón instrumental esta transformación paradigmático-cósmica y continuar creando un mundo-para-la-vida-planetaria?, ¿seremos capaces los investigadores de todas las áreas, tendencias, culturas y regiones del planeta de hacer este cambio en nuestras mentes corpóreas que permita una ciencia-conocimiento encarnada para un Buen Vivir como nos insta Leonardo Boff? (Boff, 2004, pág...).

Etimológicamente, encarnado/da proviene del participio "encarnar" del latín Incarnāre que "significa personificar, representar alguna idea, doctrina." Epistemológicamente, se sigue de la ruptura de los dualismos mente-cuerpo, mente-espíritu, razón-emoción, sujetoobjeto, civilizado-salvaje, oriente-occidente. Desde la Lingüística se puede traducir como embodied y así encontramos las expresiones embodied knowledge (conocimiento encarnado), embodied mind (mente encarnada), logos encarnado, science embodied (ciencia encarnada) (Capra (2002); Núñez Errázuriz (2001); Toro (2005); Varela $\left.\left(2000^{a}\right)\right)$.

En últimas encarnar el conocimiento, no es otra cosa que conocer desde el sí mismo (corporeidad) en relación con los otros y lo otro, lo que denominamos en la $\mathrm{CMH}$ la relación triádica yo-otro-cosmos. Y, según ello ciencia 
encarnada es conocimiento (encarnado) sistematizado (teoría de los sistemas y complejidad) elaborado mediante la puesta en escena de nuestra corporeidad-motricidad-creatividad a través de caminos investigativos encarnados organizados epistémica y no teóricamente. Es conocimiento hecho propio, enraizado, se lleva a todas partes, no se esconde, es parte vital del ser.

El tiempo de las verdades absolutas, de las cosas dadas por ciertas, de la seguridad, la simplicidad, ya no es más el tiempo de hoy. Ni siquiera el tiempo (ni como vivencia ni como concepto) es el mismo que vivíamos, tan sólo, cincuenta años atrás y aprendimos en los textos escolares de la física. Si el mundo se nos ha movido, puesto que el conocimiento es movible-devenible, es sensato pensar-sentir-imaginar que hemos de aprender, si todavía no hemos aprendido, a estar moviéndonos continuamente, a ser capaces de no aferrarnos a una verdad o a un conocimiento dado como absoluto, puesto que, a poco que miremos alrededor o dejemos pasar un poco el tiempo, nos daremos cuenta que lo que habíamos creído como verdad inamovible se ha disipado o transformado en otro conocimiento (Hawking 1987). Cada día aparecen nuevos conocimientos, fruto de la experiencia, el estudio, la investigación, la relación interpersonal, inter-cultural que no podíamos imaginar en instantes anteriores. Así fuimos, los humanos, construyendo el mundo. Unas verdades sustituyendo a otras, unos conocimientos a otros, unos descubrimientos a otros. Entonces, la incertidumbre, la inestabilidad, la inconclusión, lo inacabado debería ser la norma en la educación, la investigación, la relación. ¿Por qué nos cuesta tanto vivir y asumir lo que es el mundo-hoy?, ¿por qué nos empecinamos en querer pensar un mundo-fijo si tenemos todos los datos de lo contrario?

Es como si viviéramos escindidos, por un lado nuestra vida cotidiana compleja (incierta, autopoiética) y por otra nuestra vida investigativa simple (predeterminada, causal). ¿Qué nos está sucediendo?, ¿por qué no podemos unir y relacionar lo que ha sido separado? ¡Cuánto conocimiento-ciencia desperdiciada por nuestro orgullo occidental!, iqué triste que hayamos dejado perder los conocimientos-ciencias-filosofías-artes de los pueblos antiguos! ¿Qué nos ha sucedido? En nuestra vida nos hemos enfrentado con nosotros mismos por no poder comprender-asumir-encarnar conocimientos que provienen de lugares diversos pero que sí nos acontecen.

Cuando viajamos -física y/o virtualmente- por los distintos países, naciones, culturas de nuestro planeta, vamos poniéndonos en contacto con diversas maneras de ubicarse en el mundo, nuevos conocimientos que nos hacen trastabillar, unas veces, y otras apasionarnos. ¿Por qué nos chocan determinadas posiciones?, ¿por qué nos sentimos, muchas veces, agredidos por formas culturales-conocimientos-ciencias que se nos antojan van en contra de nuestra visión de mundo?, ¿tan difícil es integrar e incluir?, ¿tan complicado vivir la diferencia? Mas ¿no es esto la complejidad de la que todos hablamos, escribimos y sobre la que investigamos? Mi visión de este problema es que los humanos -todos, independientemente de nuestro lugar de origen- somos seres locales y adquirimos en la localidad los elementos que nos permiten comprender "ese" trocito de mundo. Ahí, vamos construyendo nuestro ser corpóreo y desde esa corporeidad actuamos, pensamos, vivimos. Lo demás, las otras localidades, son eso: otros espacios, otras culturas, los otros. Y, nos resulta muy difícil sacudirnos de la corporeidad vivida para adentrarnos en las corporeidades-otras. Lo hacemos muy bien en los escritos y los discursos pero se nos revuelve en la vivencia del día a día cuando nos fuerzan a convivir con la excesiva diferencia. Quizá, es éste uno de los elementos primarios de las luchas tribales y actuales guerras, exceptuando las luchas por el territorio.

Somos seres corpóreos y por ello, vivimos en y con la piel cada acontecimiento. Vibramos energéticamente al son de la energía universal y también en la energía de cada elemento (humano y no-humano) que constituye la vida. Pero, al habernos negado, en el mundo occidental, la corporeidad, nos han impedido aprender complejamente y la razón (pensamiento racional) no es suficiente para comprender y comprendernos en esa diferencia. $\mathrm{Si}$ a veces tenemos problemas para entendernos en la convivencia entre casi iguales, ¿cómo no asumir que nos resulte casi imposible comprendernos en la diferencia de diferentes? Pero, el mundo se ha globalizado y ahora somos obligados a ser glocales y no tribales. El problema es que no se nos han dado las herramientas para hacer ese tránsito. Nos han echado al terreno y esperan que actuemos glocalmente.

Si estamos hablando de investigación, de conocimiento, es justo saber por qué, muchas veces, nos sentimos atrapados en la "ciencia normal", en la "normativa investigativa" y en los "modelos metodológicos". Si queremos ir más allá de las normas establecidas en occidente, debemos comprender por qué nos resulta tan 
difícil abrir nuevas preguntas, construir nuevos caminos y afrontar los miedos de no cerrar las cuestiones dando por concluido un trabajo. Ser capaces de nadar en la incertidumbre, la ambigüedad, la duda, la inconclusión, la pregunta, es el gran desafío de la investigación, del conocimiento, de la ciencia y muchas veces también del arte.

Hace unos meses, se me pidió la evaluación de un trabajo de grado, llevado a cabo por un artista y educador. La primera sorpresa que me llevé, al tomar contacto con el documento, es que el autor-artista-educador, había desaparecido para dejar, en su lugar, al sujetodocumental-metodológico. Es como si a esta persona le hubieran cortado las manos de su arte y le hubieran obligado a "dictar" un discurso en un lenguaje no propio. ¡Y todo ello en función de la norma, la rigurosidad, la investigación!

Entonces nos queda mucho por estudiar, comprender, aceptar y asumir como seres corpóreos. Bajarnos de los pedestales (racionales) a los que nos hemos encaramado para compartir con la diferencia y los diferentes y, ahora sí, juntos pero no revueltos (no podemos ni debemos perder la diferencia -fundamento de la vida-) pensar el mundo, los reales problemas que nos acosan (y que no son los que los mas media nos hacen ver) y responsable y comprometidamente atrevernos a proponer modos alternativos de vida. Para ello, los investigadores-todos del mundo, independientemente de nuestras áreas de conocimiento, procedencias y tendencias, tenemos una gran tarea por delante: construir las preguntas básicas, las preguntas que nos permitan pensar alternativas al mundo de la vida. No las preguntas-norma, no las preguntas fáciles, sino las preguntas que nos lleven a más preguntas y nos fuercen a pensar por caminos diferentes a los que, hasta ahora, hemos pensado. No es ir hacia atrás, todo lo contrario, es aprovechar la extensión y profundidad del conocimiento existente en el planeta, para mirar adelante y abrirnos nuevas rutas que nos permitan continuar viviendo. ¿No es suficiente?

Para ello, deberemos valernos de todas las capacidades y habilidades que tenemos los seres humanos. No quedarnos atrapados en el pensamiento lógico-deductivo-argumentativo desconociendo las posibilidades que nos ofrece la imaginación, la ensoñación, la intuición, la emoción, la razón, la metáfora, etc., así como los diferentes lenguajes con los cuales nos comunicamos. El hecho, que en la sociedad occidental, hayamos dispues- to el alfabeto (oral y escrito) como el lenguaje "válido" para la construcción de conocimiento, no significa que sea el único lenguaje por el cual los humanos construimos conocimiento. Permanecer en esta verdad, no nos va a ayudar a resolver la problemática. Quizá, nos parezca extraño, todavía, admitir que los lenguajes simbólicos (música, canto, danza, pintura, gesto, cine, fotografía) tienen, muchas veces, más poder para transformar la realidad que el propio lenguaje oral y escrito (matemática y literatura). ¿Cuántas veces nos hemos despertado de nuestro analfabetismo cultural y en nuestra sensibilidad, en una película, una exposición fotográfica, una obra de teatro? ¿Por qué empecinarnos que los pueblos-danzantes no construyen conocimiento-ciencia-filosofía? ¿No puede ser ese orgullo occidental el que quizá esté entorpeciendo los procesos de comprensión en la diferencia?, ¿será la envidia y la falta de comprensión en las maneras-otras de ser y estar en el mundo?, ¿no ha sido la misma física cuántica occidental que ha tenido que admitir "lo no-visible" para comprender la materia? (Sheldrake 1995).

Todo esto es, desde nuestro punto de vista, encarnar el conocimiento. Es decir, conocer desde nuestra subjetividad, desde nuestro ser complejo corpóreo, desde todas y cada una de las capacidades y dimensiones que nos constituyen como humanos y eso en relación con los otros seres con quienes compartimos el planeta. Es una apuesta de esperanza por la vida, un desafío que todavía podemos emprender la especie humana. Bajarnos de los pedestales de las verdades instituidas, hacernos más humildes y ponernos a trabajar, todos, en otros derroteros. ¿Una utopía? Recordemos que los sueños de hoy son las realidades de mañana y que solamente soñando, imaginando otras realidades es que podemos transformar la existencia del hoy.

A partir de lo dicho definimos Investigación encarnada como el estudio de los diversos procedimientos corpóreos que empleamos para descubrir los entresijos de un problema que me (nos) afectan como ser/es humano/s en el mundo (soy humano y nada de lo que es humano me es ajeno). La investigación no es aséptica ni imparcial, de la misma manera que no hay cienciaconocimiento encarnado aséptico y apolítico. Toda investigación tiene una carga afectiva, porque es un ser humano complejo (emocional, espiritual, físico, mental, mágico, sensitivo, intuitivo) quien elige qué investigar y cómo investigar, qué mirar y como mirar. 
Dejamos para próxima ocasión, el desarrollo de los principios de la ciencia encarnada, que por falta de espacio en este artículo, no nos es posible exponer.

\section{BIBLIOGRAFÍA}

[1] Aristizábal, M., y E. Trigo. La formación doctoral en América Latina. ¿Más de lo mismo?, ¿una cuestión pendiente? Colombia-España: iisaber, 2009.

[2] Boff, L. Ecologia: grito da Terra, grito dos Pobres. Río de Janeiro: Sextante, 2004.

[3] Botero Uribe, D. Manifiesto del pensamiento latinoamericano. Bogotá: Magisterio, 2000.

[4] Capra, F. Las conexiones ocultas. Implicaciones sociales, medioambientales, económicas y biológicas de una nueva visión del mundo. Barcelona: Anagrama, 2002.

[5] DRAE. Diccionario de la Real Academia de la Lengua Española.

[6] Hawking, S.W. Historia del tiempo. Del big bang a los agujeros negros. Barcelona: Grijalbo, 1987.

[7] Morín, Edgar. La noción de sujeto. En Nuevos paradigmas, cultura y subjetividad, Vol. 1. Barcelona: Paidós, 1994.

[8] Núñez Errázuriz, R. Mente-cuerpo: una vieja falacia. El Mercurio domingo 21 octubre, 2001.

[9] Sérgio y otros. La ciencia de la motricidad humana $(\mathrm{CMH})$ como área autónoma de conocimiento: trayectorias desde la Red Internacional de Investigadores en Motricidad Humana. Integração 46, 2006, 247-262.

[10] Sheldrake, R. Siete experimentos que pueden cambiar el mundo. Barcelona: Paidós, 1995.

[11] Toro, S. Corporeidad y lenguaje: la acción como texto y expresión. Cinta de Moebio 37, 2010, 44-60.

[12] Trigo, E. Creatividad y Motricidada. (Barcelona): Inde, 1999.

[13] Trigo, E., y S. Toro. Hacia una de-construcción del concepto de ciencia. En ¿Recorre la civilización el mismo camino que el sol? Pedagogía, Subjetividad y Cultura, 13-34. Popayán: Fondo Editorial Universidad del Cauca, 2006.

[14] Varela, F. El fenómeno de la vida. [Santiago de Chile]: Dolmen, 2000a.

[15] Varela, F. Francisco Varela y la Mente Encarnada. http://www.inalambrico.reuna.cl/fichas/entrevistas/ francisco_varela.htm 2000b.

[16] Zemelman, H. Voluntad de conocer. El sujeto y su pensamiento en el paradigma crítico. Madrid: Anthropos, 2005.

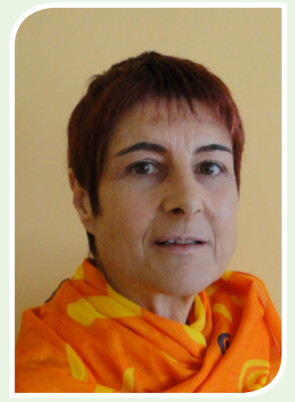

Eugenia Trigo Aza

Doctora en Filosofía y Ciencias de la Educación por la UNED (1989). Doctora en Educación por la UDC (1999). Ha sido profesora de Preescolar, Educación Básica y Secundaria (Vigo, Pontevedra y Santiago, 1975-1994). Profesora titular en la Universidad de A Coruña (1994-2001), en el Instituto Superior Universitario de Maia (Portugal, 2001-2003), en la Universidad del Cauca (Colombia, 2004-2009), actualmente se desempeña como Docente en la Universidad Tecnológica Equinoccial (Ecuador). 